\title{
\#USGS
}

Prepared in cooperation with Pinellas County, Southwest Florida Water Management District, and Tampa Bay Water

\section{Comparative Hydrology, Water Quality, and Ecology of Selected Natural and Augmented Freshwater Wetlands in West-Central Florida}

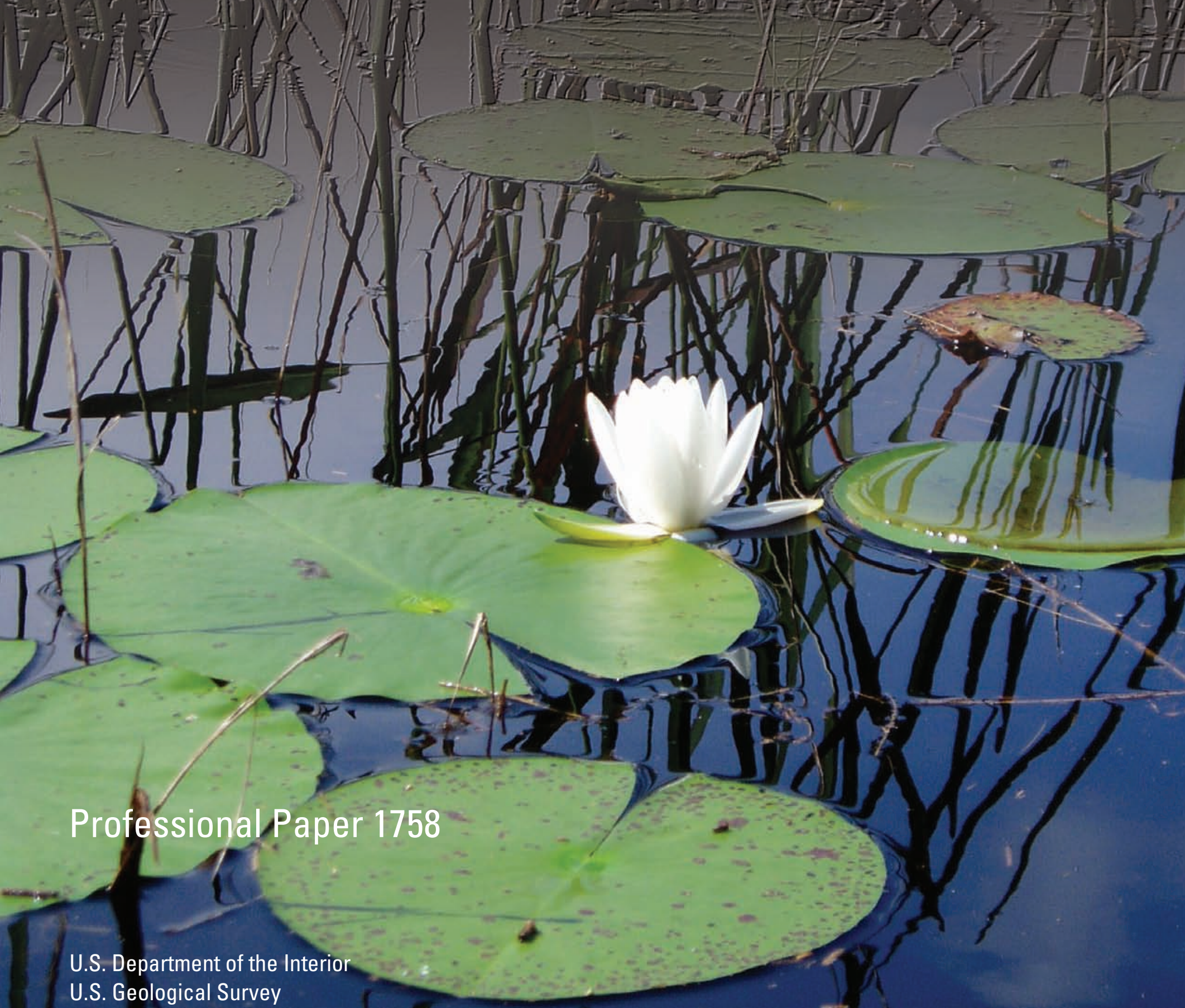


